Open Access

\title{
Comparison in dietary patterns derived for the Canadian Newfoundland and Labrador population through two time-separated studies
}

\author{
Zhi Chen ${ }^{1}$, Peizhong Peter Wang ${ }^{1 *}$, Lian Shi ${ }^{1}$, Yun Zhu ${ }^{1}$, Lin Liu' ${ }^{1}$ Zhiwei Gao ${ }^{2}$, Janine Woodrow ${ }^{1}$ \\ and Barbara Roebothan'
}

\begin{abstract}
Background: While a dietary pattern is often believed to be stable in a population, there is limited research assessing its stability over time. The objective of this study is to explore and compare major dietary patterns derived for the Canadian subpopulation residing in Newfoundland and Labrador (NL), through two time-separated studies using an identical method.

Methods: In this study, we derived and compared the major dietary patterns derived from two independent studies in the NL adult population. The first study was based on the healthy controls from a large population-based case-control study (CCS) in 2005. The second was from a food-frequency questionnaire validation project (FFQVP) conducted in 2012. In both studies, participants were recruited in the same manner and dietary information was collected by an identical self-administered food-frequency questionnaire (FFQ). Exploratory common factor analysis was conducted to identify major dietary patterns. A comparison was conducted between the two study populations.
\end{abstract}

Results: Four major dietary patterns were identified: Meat, Vegetables/fruits, Fish, and Grains explaining $22 \%, 20 \%$, $12 \%$ and $9 \%$ variance respectively, with a total variance of $63 \%$. Three major dietary patterns were derived for the controls of the CCS: Meat, Plant-based diet, and Fish explaining $24 \%, 20 \%$, and $10 \%$ variance respectively, with a total variance of $54 \%$. As the Plant-based diet pattern derived for the CCS was a combination of the Vegetables/ fruits and Grains patterns derived for the FFQVP, no considerable difference in dietary patterns was found between the two studies.

Conclusion: A comparison between two time-separated studies suggests that dietary patterns of the NL adult population have remained reasonably stable over almost a decade.

Keywords: Dietary habits, Dietary patterns, Nutrition epidemiology, Newfoundland and Labrador population

\section{Introduction}

Most nutritional epidemiological literature addresses the use of nutrients or individual food items to assess possible associations between diet and health. There are several limitations of the single-nutrient approach: people eat meals consisting of a variety of foods rather than isolated nutrients; single-nutrient analysis does not account for complicated interactions among nutrients

\footnotetext{
* Correspondence: pwang@mun.ca

${ }^{1}$ Division of Community Health and Humanities, Faculty of Medicine, Memorial University of Newfoundland, St. John's, NL A1B 3V6, Canada Full list of author information is available at the end of the article
}

[1]; and nutrient effects are difficult to examine individually by single-nutrient analysis due in part to high levels of nutrient-nutrient interactions (for example, potassium and magnesium) [2]. Moreover, single-nutrient analysis may be confounded by each individual's dietary pattern which is commonly associated with nutrient intakes [3, 4]. In order to overcome these limitations, an emerging approach in nutritional epidemiology is to use dietary patterns rather than isolated nutrients. Compared to the traditional approaches used in previous nutritional epidemiology, dietary pattern analysis considers how food and nutrients are consumed in combination and could 
therefore provide a more accurate and comprehensive description of dietary exposure in a certain population [4-6].

Support for the use of dietary pattern analysis has been growing. People's eating habits usually remain relatively stable unless they experience such major changes in their personal circumstances as getting married, changing geographic location or receiving a serious warning from a health professional that their current diets have significant and negative impacts on their health. Many factors influence food choice including family income, food prices, individual preferences and beliefs, cultural traditions and customs, as well as geographic and environmental factors $[7,8]$. While a dietary pattern is often believed to be relatively stable in a population, limited research has assessed its degree of stability over time. The objectives of this study were 1) to identify the major dietary patterns of an NL population from two time-separated studies using identical methods and 2) to explore whether there were differences in these dietary patterns between these two studies conducted several years apart.

Our large and multidisciplinary research team, including more than 40 researchers residing in the provinces of Ontario (ON) and NL, Canada, has published several journal articles on diet of the NL adult population using both nutrient and dietary pattern methods [9-13]. Using exploratory common factor analysis, this study derived and compared major dietary patterns from dietary data collected by use of a food-frequency questionnaire (FFQ) in two projects conducted with the NL population, a population-based case-control study (CCS), $2001-2005$ $[14,15]$, and a food-frequency questionnaire validation project (FFQVP), 2012 [16].

\section{Methods}

\section{Study participants}

The CCS was conducted from 2001 to 2005 and a detailed description of selecting the population controls can be found elsewhere [17]. Briefly, eligible cases were newly diagnosed colorectal cancer patients. Controls were frequency-matched with cases by sex and age on 5 -year strata. Both cases and controls were selected from NL residents, aged from 20 to 74 years. They were identified through random digit dialing using phone numbers provided by a NL phone company (Aliant). By July 2005, a total of 2168 eligible controls were contacted for further survey and 1603 controls agreed to participate. Those persons who agreed to participate were sent a survey package, comprised of a written consent form, a personal history questionnaire (PHQ), and a food-frequency questionnaire (FFQ). Of these, 717 participants completed and returned the survey package with a response rate of $44.7 \%$. Current study participants were part of the population controls from the CCS project, aged from 35 to 70 years.
The FFQVP was conducted between February 2011 and May 2012, by the Health Research Unit of Memorial University. This study population was sampled by stratified random digit dialing with proportional allocation methodology. Participants were recruited in the same manner as was used by the CCS. All were noninstitutionalized adult residents of NL, aged 35-70 years. Residence in NL was defined as having lived in the province for at least two years prior to the beginning of the study. Other inclusion criteria included a minimum of an $8^{\text {th }}$ grade level of English speaking and reading skills and no cognitive impairment, psychological conditions, or pregnancy. From a list of phone numbers (landlines and cell phones) provided by Info Canada, an initial sample of 450 persons was recruited randomly by telephone. After exclusion, 306 participants were identified as potential respondents and mailed a survey package containing a written consent form and a FFQ. Finally, 205 individuals completed and returned the survey package, giving a response rate of $67 \%$.

Data from FFQs with 20 continuous blanks or reporting energy intakes outside the range of $500-5000 \mathrm{kcal}$ were excluded [18]. After exclusion, a total of 554 participants of the former population and 192 participants of the current population remained and data provided by them were entered into further analysis (Fig. 1).

\section{Data collection}

For both studies, a modified FFQ, based on the wellknown Hawaii FFQ, was used to gather dietary intake data. The original Hawaii FFQ was used in Hawaii/Southern California to assess the general food intake of a multiethnic population [19]. It has been validated and widely used in the United States [20-22]. In our new version of the FFQ, some food items unusual to the NL population (for example, tamales and ham hocks) were deleted or altered, and some items commonly consumed in NL (for example, cloudberries/bake-apples, game meats, and pickled/smoked fish) were added. The food items listed in the NL FFQ, which has been validated by our team [16], include nine major categories: beverages, dairy products, mixed dishes, vegetables, meat and fish, cereals and grains, fruits, desserts and sweets, and miscellaneous.

Dietary assessments of participants using data collected via this FFQ were carried out 12-24 months prior to conducting a telephone interview. During the interview each participant was required to recall food intake over the past 24 months - the frequency of each food item consumed, the number of servings, and the approximate size of portions habitually consumed at a single sitting. The units of frequency ranged from per day, per week, per month to rarely or never, and the portion sizes included standard and smaller or larger than standard (standard $\pm 25 \%$ ). A standard serving size 


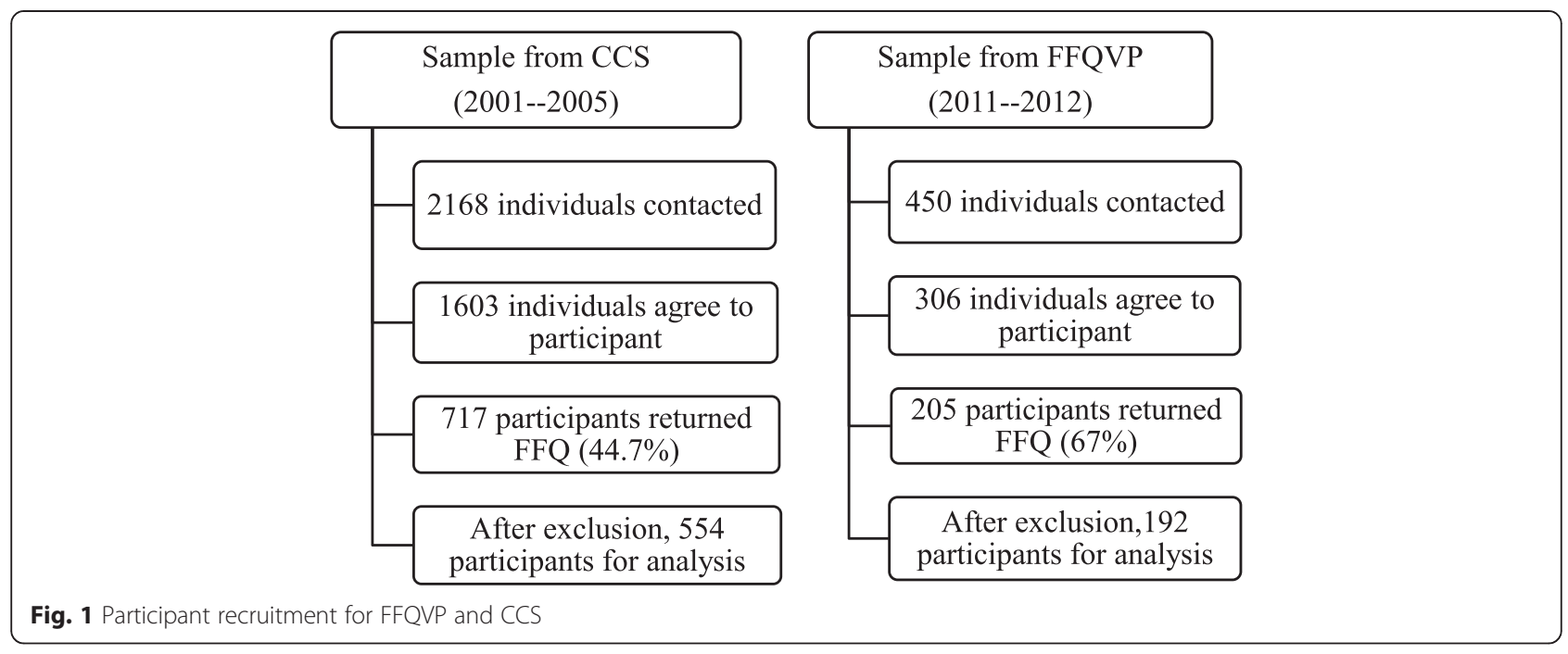

for each food item or beverage was described on the FFQ in common household measures and grams. The FFQ also included food photographs to indicate standard portion sizes.

Except for several independent food items, the 169 food items were categorized into 39 predefined food groups, based on their nutritional characteristics and their role in the diet (Table 1). Independent food items comprised their own groups, given that they could not be appropriately combined with others, for example, eggs, beer, jam, and fruit pies. Total energy and nutrient intakes for individuals were calculated according to the composition values from the 2005 Canadian Nutrient File (CNF) and the Elizabeth Stewart Hands and Associations (ESHA) Food Processor database software [23].

The study sample from the CCS was administered a PHQ to collect socio-demographic and medical information including age, sex, date of birth, marital status, educational attainment, medical history (for example, history of diabetes or high cholesterol), bowel screening history, medication use (for example, multivitamins and nonsteroidal anti-inflammatory drugs), alcohol and tobacco use, reproductive factors, self-reported physical activity and other information.

Less extensive socio-demographic information was gathered as part of the telephone interview with the study population in FFQVP. This included age, sex, size of community, marital status, employment status, level of education, and smoking habits.

\section{Statistical analyses}

The appropriateness of factor analysis for each study sample was verified by Bartlett's Test of Sphericity (BTS) and the Kaiser-Meyer-Olkin (KMO) measurement. BTS was used to test the homogeneity of variances and KMO measurement was conducted for testing sampling adequacy. KMO values could not be less than 0.5 to ensure the suitability of factor analysis use in this study [24]. Exploratory common factor analysis was used for factor extraction, and orthogonal rotation (varimax option) was used for simpler structures with greater interpretability. A factor was retained when it met the following criteria: factor eigen value $>1.50$, identification of a break point in the scree plot (the difference between each two points becomes small suddenly), the proportion of variance explained (at least $50 \%$ of variance in this study), and factor interpretability (the fewer the factors, the greater the interpretability). A rotated loading matrix described the strength and direction of the associations between the retained factors and food groups. If a food group had a factor loading $\geq 0.5$ (for the FFQVP population) or $\geq 0.35$ (for the CCS population), it was loaded on a factor. We also retained food groups that had negative correlations $(\leq-0.2)$ to incorporate the valuable information concerning infrequently consumed foods within each factor [25]. Dietary patterns were named according to the characteristics of food groups loaded on a retained factor.

Differences in demographic information between the two study populations were detected by $t$-test and chisquare test. Statistical analyses were performed using the Statistical Analysis System (SAS, version 9.2) software. Differences with $p$-value $<0.05$ were considered to be statistically significant.

\section{Ethics statement}

This research was approved by the HREB at Memorial University of Newfoundland. (Reference number 14.098).

\section{Results}

\section{Demographic information}

In total, the study sample was made up of 554 participants from the CCS population and 192 participants 
Table 1 Food groups used in the dietary pattern analysis

\begin{tabular}{ll}
\hline Food group & Food items \\
\hline Milk & Whole milk, 2\% milk, skim milk, milk shake \\
Yogurt & Yogurt drink, yogurt (regular/light, plain/fruit/frozen) \\
Coffee & Coffee (regular/decaffeinated) \\
Tea & Tea (regular/herbal) \\
Sugar & Sugar (in tea/coffee)
\end{tabular}

Soft drinks

Cola, Pepsi, diet/other soft drinks

Egg

Cheese

$\begin{array}{ll}\text { Mixed dishes } & \text { Soups (creamed), pasta (with meat sauce), } \\ & \text { mixed dishes (with cheese), pizza (with meat), } \\ & \text { meat stew with vegetables, chili with meat }\end{array}$

Egg (boiled/fried)

Cream cheese (regular fat), cheese (regular fat, light, ultra light), cottage, ricotta cheese

Red meat

Ground beef (regular/medium/lean), roast beef, steak, pork chop, roast pork, baked ham, bacon, veal, lamb, hot dog, wiener, sausage, corned beef, cold cuts

Game

Sea-bird, seal, caribou, moose, partridge, other wild birds

Cured/processed Baked ham, bacon, hot dog, wiener, corned beef, red meat cold cuts, salted/dried meat, pickled meat

Cured/processed Baked ham, bacon, hot dog, wiener, corned beef, meat

Poultry

Fish

Processed fish

Fruit juice

Other fruit

Root vegetables cold cuts, fried chicken, salted/dried meat, pickled meat, fried/canned/smoked/salted/dried/pickled fish

Fried chicken, chicken (roasted or stewed/skin removed)

Shellfish, fish (baked or broiled), fried/canned/ smoked/salted/dried/pickled fish

Canned/smoked/salted/dried/pickled fish

Orange/grapefruit/apple/grape/other fruit juice, fruit drinks/lemonade, iced tea

\section{Other fruit}

Apple, pear, grape, banana, beach, plum, nectarine, apricot, cantaloupe, watermelon, honeydew melon, mango, papaya, apple sauce, all other fruit with the exception of berries

Cruciferous

vegetables

Other green

Beans, peas

Tomato sauce

Other vegetables

Potatoes (mashed, baked), fried potatoes/French fries, carrots (raw or cooked)

Broccoli, cabbage, coleslaw, cauliflower, asparagus or brussel sprouts

Spinach/other green-leaf vegetables, green salad

Peas, lima beans, green/yellow beans, beans/lentils, pea soup

Tomatoes (fresh/canned), ketchup

Corn, cucumber, onions, beets, yellow squash, zucchini or eggplant, sweet pepper, bean sprout, avocado, other vegetables

Total cereals and grains
Bran or granola cereal, whole wheat cereals, cereals (not sugar coated), hot cereals, sugar coated cereals, other breakfast cereals, sugar on cereal, $100 \%$ whole grain/dark bread, $60 \%$ whole grain/light rye, white bread, white bread rolls, whole wheat rolls, crackers, bran/oat muffin, other muffins, pancake, waffles, macaroni, spaghetti, noodles, rice, crisp snacks
Table 1 Food groups used in the dietary pattern analysis (Continued)

\begin{tabular}{ll}
\hline Whole grains & $\begin{array}{l}\text { Whole wheat cereals, } 100 \% \text { whole grain/dark bread, } \\
60 \% \text { whole/light rye, whole wheat rolls }\end{array}$ \\
$\begin{array}{l}\text { Dessert and } \\
\text { sweet }\end{array}$ & $\begin{array}{l}\text { Cakes, pies and tarts, donuts and sweet rolls, } \\
\text { cookies, iced cream, light or diet ice cream, } \\
\text { pudding, diet or light pudding, jell-o, popsicles, } \\
\text { freezies, candy (with/without chocolate) }\end{array}$ \\
Vegetable juice & Vegetable juice \\
Beer & Beer, ale \\
Whiter wine & White wine \\
Red wine & Red wine, sherry \\
Liquor & Liquor \\
Citrus & Citrus fruits \\
Berries & Berries \\
Dried fruits & Dried fruits \\
Canned fruits & Canned fruits \\
Pies, tarts & Pies, tarts \\
Jam, jelly & Jam, jelly, honey syrup \\
Pickled vegetables & Pickles, relish
\end{tabular}

from the FFQVP population. All of the study participants were aged 35-70 years. Individuals from the CCS $(58.7 \pm 7.7)$ were significantly older than those from the FFQVP $(56.2 \pm 8.7)$. The gender distributions between the two populations were significantly different $(p<0.0001)$. The percentage of males in the CCS (58.1\%) was much higher than in the FFQVP study (22.4\%). Also, distributions of education attainment and marital status between these two study groups were significantly different (Table 2).

Table 2 Demographic information of study participants from both CCS and FFQVP

\begin{tabular}{llll}
\hline Demographic information & CSS & FFQVP & $P^{\text {a }}$ \\
\hline Age $($ mean \pm SD) & $58.7 \pm 7.7$ & $56.2 \pm 8.7$ & $<0.0001$ \\
Sex & & & $<0.0001$ \\
$\quad$ Male & $322(58.1 \%)$ & $43(22.4 \%)$ & \\
$\quad$ Female & $232(41.9 \%)$ & $149(77.6 \%)$ & \\
Marital Status & & & $<0.0001$ \\
$\quad$ Single & $17(2.9 \%)$ & $15(7.8 \%)$ & \\
Separated/divorced/widowed & $74(13.4 \%)$ & $26(13.5 \%)$ & \\
$\quad \begin{array}{l}\text { Married/living together } \\
\text { Level of education }\end{array}$ & $463(83.7 \%)$ & $151(78.7 \%)$ & \\
$\quad$ & & & $<0.0001$ \\
Some school without & $156(28.4 \%)$ & $27(14.0 \%)$ & \\
high school certificate & & & \\
High school certificate & $300(54.6 \%)$ & $51(26.6 \%)$ & \\
Post-secondary education & $98(17 \%)$ & $114(59.4 \%)$ & \\
\hline ap value from $t$ test within CCS and FFOVP groups & &
\end{tabular}




\section{Factor analysis}

The observed KMOs for the two populations were 0.68 for the CCS and 0.60 for the FFQVP suggesting that the two samples from different populations were adequate for factor analysis. $P$ values from the BTS were $<0.0001$, suggesting homogeneity of variance across the samples. Figure 2 shows the scree plots for both study populations. For the CCS sample, the first three eigenvalues, $3.73,3.24$, and 1.56, drop substantially. After the fourth eigenvalue (1.43), the values remain more consistent (1.39 for the fifth, and 0.89 for the sixth). As a result, the third point is considered a break point. As for the FFQVP sample, differences between each two eigenvalues change to gentle from sharp after the fourth value. Accordingly, the fourth point is regarded as a break point on this plot. All eigenvalues before each break point are greater than 1.50. Combined with total variance explained and factor interpretability, a 3-factor solution was selected for the study population from CCS. This explained $54 \%$ of variance. The first four factors were retained for the study population from FFQVP, and this explained $63 \%$ of variance (Table 3).
According to the results obtained from the factor loading matrix shown in Table 3, the retained factors were labelled, depending on the given food groups loaded on them. A factor loading $\geq 0.35$ of a certain food group indicated a greater contribution of that food group to the specific pattern for the CCS population. The three retained factors were identified as three dietary patterns and were labelled Meat, Plant-based diet, and Fish. The first pattern was defined as the Meat pattern, and characterized by high loadings for red meat, cured/processed red meat, cured/processed meat, and mixed dishes. The second pattern, which loaded heavily on fruits, cruciferous vegetables, other green vegetables, beans, peas, other vegetables, tomato sauce, total cereals and grains, and whole grains, was labelled the Plant-based diet pattern. The final pattern was named Fish because it had high loadings of fish, processed fish, berries and other local fruits and negative loadings in the food groups of cheese.

The four retained factors were identified as four dietary patterns for the FFQVP population and were labelled Meat, Vegetables/fruits, Fish, and Grains. The fourfactor dietary pattern was identified based on the results
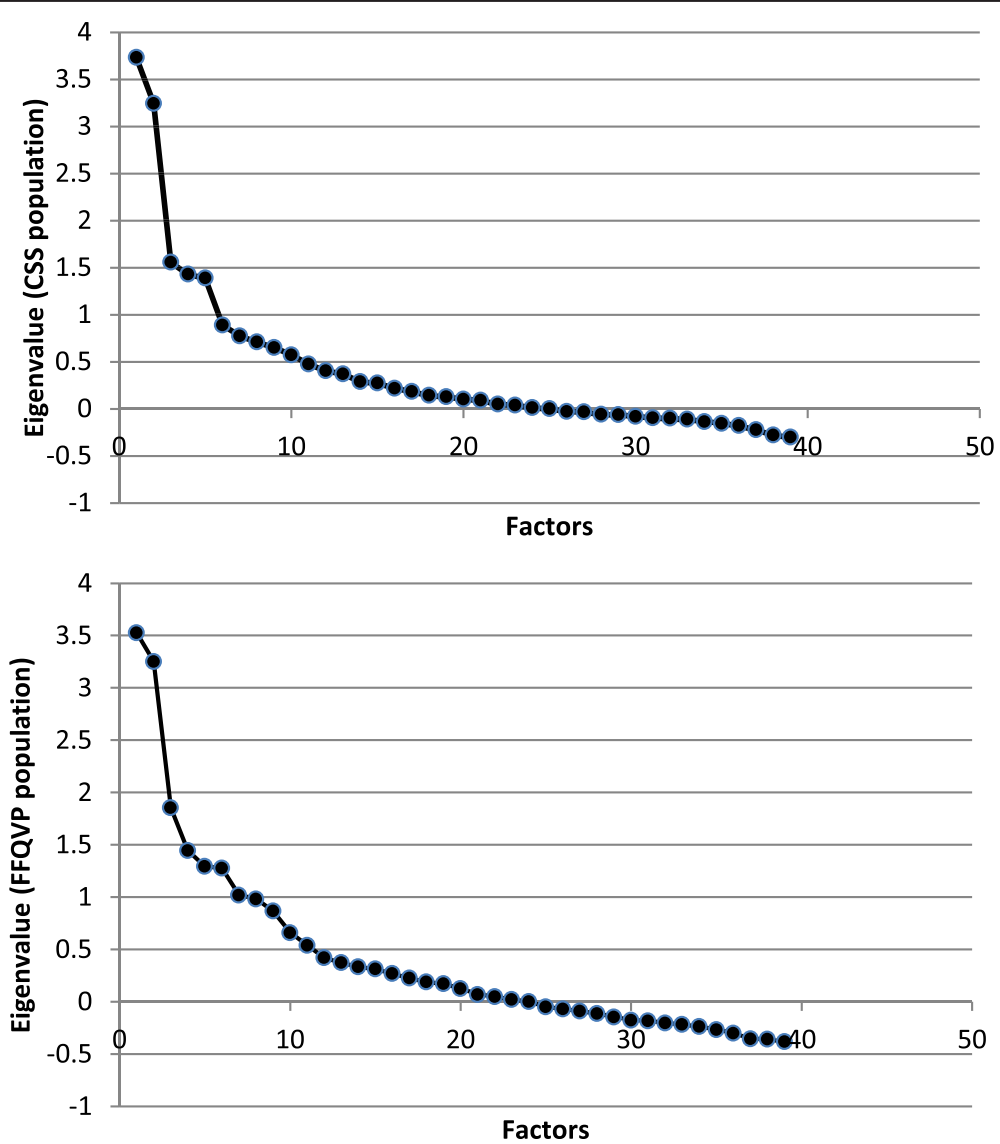

Fig. 2 Scree plots for eigenvalues from factor extraction in two studies 
Table 3 Factor Loadings and Explained Variances (VAR) of the Major Dietary Patterns identified in two studies, using an exploratory common factor analysis

\begin{tabular}{|c|c|c|c|c|c|c|}
\hline \multirow[t]{3}{*}{ Food groups } & \multicolumn{6}{|c|}{ Factor loadings $^{\mathrm{a}}$} \\
\hline & \multicolumn{4}{|c|}{ Current population } & \multicolumn{2}{|c|}{ Former population } \\
\hline & Meat & Vegetables/Fruits & Fish & Grain & Meat & Plant-based diet \\
\hline
\end{tabular}

\begin{tabular}{|c|c|c|c|}
\hline \multicolumn{4}{|l|}{ Milk } \\
\hline \multicolumn{4}{|l|}{ Yogurt } \\
\hline \multicolumn{2}{|l|}{ Coffee } & \multicolumn{2}{|c|}{-0.31} \\
\hline \multicolumn{4}{|l|}{ Tea } \\
\hline \multicolumn{4}{|l|}{ Sugar } \\
\hline \multicolumn{2}{|l|}{ Soft drinks } & \multicolumn{2}{|c|}{-0.20} \\
\hline \multicolumn{4}{|l|}{ Egg } \\
\hline \multicolumn{4}{|l|}{ Cheese } \\
\hline \multicolumn{2}{|l|}{ Mixed dishes } & & 0.43 \\
\hline Red meat & 0.83 & & 0.88 \\
\hline \multicolumn{4}{|l|}{ Game } \\
\hline Cured/processed red meat & 0.90 & & 0.91 \\
\hline Cured/processed meat & 0.93 & & 0.92 \\
\hline
\end{tabular}

Poultry

Fish

Processed fish

Fruit juice

Other fruits

Root vegetables

Cruciferous vegetables

Other greens

Beans, peas

Desserts and sweets

Vegetable juice

Beer

White wine

Red wine

Liquor

Citrus

Berries

Dried fruit

Canned fruit

Pies, tarts

Jam, jelly

Pickled vegetables

Proportion of VAR explained (\%)

$\begin{array}{ll}22 \% & 20 \% \\ 22 \% & 42 \%\end{array}$

$12 \%$ 
retained from the factor loading matrix (Table 3), where a higher factor loading of a given food group indicated a greater contribution of that food group to the specific pattern. The first pattern was labelled because of a high intake of red meat, cured/processed meat, and cured/ processed red meat. The Vegetables/fruits pattern indicates a preference for several vegetable/fruit groups, including greens, tomato sauce, berries, and other vegetables. The Fish pattern had an emphasis on fish and processed fish. We named the final pattern Grains, since it was characterized by a high consumption of whole grains, cereals, and grains, and a low consumption of beer, white wine, and coffee.

\section{Discussion}

Even though dietary pattern analysis has emerged as a possible approach examining possible diet-health relationship, little research has been conducted to assess the stability of dietary patterns derived for an identical population over time. In this study, we compared the major dietary patterns derived from two time-separated studies of the NL adult population assessed by a selfadministered comprehensive FFQ.

The present study derived a three-factor dietary pattern for the CCS and a four-factor dietary pattern for the FFQVP. We observed both similarities and differences in dietary patterns between the two studies. The total variances explained for the CCS and FFQVP studies were similar, $54 \%$ and $63 \%$, respectively. Both identified meat and plant-based food as the top two major factors, which in combination explained almost equal amounts of variation ( $42 \%$ and $44 \%$ ). According to the factor loading matrix, the patterns labelled Meat pattern and Fish pattern derived for the CCS were largely the same as those two derived from the FFQVP. The meat pattern was similar to the Western pattern of many previous studies [26, 27] in the food items contained (for example, red meat, processed meat, other high-fat food). This pattern has been positively associated with cancer [28], cardiovascular diseases [29, 30], and obesity [31]. The Fish pattern, which is characterized by high intakes of fish and processed fish, seems to be different from any pattern described in other research. Geographic isolation and the historical importance of the cod fishery in NL may be the leading cause of this unique phenomenon [32]. The Plant-based diet pattern derived for CCS was a combination of the Vegetable/fruit and Grains pattern in the FFQVP. This pattern is comparable to the Prudent and/or Vegetable/fruit patterns described in other studies, with a high consumption of vegetables, fruits, and other plant-based foods [26, 33, 34], and has been reported to have a protective effect against coronary heart disease [35], type 2 diabetes [26] and CRC [36]. Also, the main food items of whole grain, cereals and grains from the Grains pattern can contain substantial sources of dietary fibre, consumption of which has been shown to be beneficial to health, especially by decreasing the risk of chronic diseases such as CRC [25, 37, 38].

According to findings obtained from the FFQVP and CCS, we conclude that dietary patterns derived by exploratory common factor analysis for those two studies are almost the same, except for the number of factors retained and total variance explained by the retained patterns. These minor differences may be attributed to several reasons. First of all, the sample size may be too small to be representative of the whole population as there were only 554 study participants from the CCS and 192 from the FFQVP. Secondly, distributions of sex and age between the two study populations were significantly different. There were more males in the CCS than in the FFQVP. According to previous studies, dietary patterns are likely to vary between genders as well as age groups. For example, an association between women and higher loadings on healthy dietary patterns has been reported by previous studies [30, 33, 39]. Also, according to one of our earlier studies, older people are more likely to follow a healthier dietary pattern according to results from multivariable linear regression [40]. However, small sample size (stratified by sex or age groups) limited us to conduct factor analysis in this study. Additionally, study participants from the CCS were controls to the CRC cases, and therefore likely to be family members of the cases or diagnosed persons and thus interested in cancer and/or its possible association with nutritional factors. Such individuals may not be able to truly represent the general population. However, study participants in the FFQVP were randomly recruited from the general population. Further, information bias may exist because study participants were required to recall their dietary intakes one or two years prior to the interview or survey.

This study is the first nutritional epidemiological research conducted in the NL population to compare major dietary patterns derived from two independent studies using an identical method but conducted nearly a decade apart. The results of this study provide an overall picture of the dietary exposure of the NL adult population and updated information on the current dietary habits of residents of the province. In addition, this study will provide guidance and reference for future researchers to conduct related studies on this topic through an improved method and study design.

\section{Conclusion}

After a comparison was made of the dietary patterns followed by participants of two separate studies conducted at two different times (FFQVP and the CCS projects), no considerable differences were found. Therefore we conclude that the major dietary patterns followed by 
the NL adult population have been reasonably stable for almost a decade. However, because of issues on methodology and study design, further investigations to determine the reproducibility and validity of the dietary pattern analysis assessed by the FFQs should be conducted in the future.

\section{Abbreviations}

BTS: Bartlett's Test of Sphericity; CNF: Canadian Nutrient File; CRC: Colorectal cancer; CSS: Case-control study; ESHA: Elizabeth Stewart Hands and Associations; FFQ: Food-frequency Questionnaire; FFQVP: Food-frequency questionnaire validation project; KMO: Kaiser-Meyer-Olkin; NFCCR: Newfoundland Familial Colorectal Cancer Registry; NL: Newfoundland and Labrador; ON: Ontario; PHQ: Personal history questionnaire; SAS: Statistical Analysis System.

\section{Competing interests}

The authors declare that they have no competing interests.

\section{Authors' contributions}

PPW contributed to the conception and design of this manuscript. ZC conducted the research, data analysis and paper writing. PPW, LS, YZ, LL, JW, ZG and BR subsequently revised the manuscript. All authors have read and approved the final manuscript.

\section{Acknowledgement}

This work is part of Z.C.'s thesis project, which was supported through the Faculty of Medicine's Dean's Fellowship, Shree Mulay Community Health Graduate Student Award, and a NLCAHR's Master Research grant provided to Z.C. We wish to extend our appreciation to all study participants for their time, efforts, and cooperation.

\section{Author details}

'Division of Community Health and Humanities, Faculty of Medicine, Memorial University of Newfoundland, St. John's, NL A1B 3V6, Canada. ${ }^{2}$ Clinical Epidemiology Unit, Faculty of Medicine, Memorial University of Newfoundland, St John's, NL, Canada.

\section{Received: 2 February 2015 Accepted: 27 July 2015}

\section{Published online: 01 August 2015}

\section{References}

1. National Research Council, Committee on Diet and Health. Diet and health: implication for reducing chronic disease risk. Washington, DC: National Academy Press; 1989.

2. Lee CN, Reed DM, MacLean CJ, Yano K, Chiu D. Dietary potassium and stroke. N Engl J Med. 1988;318:995-6.

3. Kant AK, Schatzkin A, Block G, Ziegler RG, Nestle M. Food group intake patterns and associated nutrient profiles of the US population. J Am Diet Assoc. 1991;91:1532-7.

4. Randall E, Marshall JR, Graham S, Brasure J. Patterns in food use and their associations with nutrient intakes. Am J Clin Nutr. 1990;52:739-45.

5. Huijbregts PP, Feskens EJ, Kromhout D. Dietary patterns and cardiovascular risk factors in elderly men: the Zutphen Elderly Study. Int J Epidemiol. 1995;24:313-20.

6. Huijbregts P, Feskens E, Rasanen L, Fidanza F, Nissinen A, Menotti A, et al. Dietary pattern and 20 year mortality in elderly men in Finland, Italy, and The Netherlands: longitudinal cohort study. BMJ. 1997;315:13-7.

7. Franchi M. Food choice: beyond the chemical content. Int J Food Sci Nutr. 2012;63 Suppl 1:17-28.

8. Diet, nutrition and the prevention of chronic diseases. World Health Organ Tech Rep Ser. 2003; 916:i-viii. 1-149, backcover.

9. Zhu Y, Wu H, Wang PP, Savas S, Woodrow J, Wish T, et al. Dietary patterns and colorectal cancer recurrence and survival: a cohort study. BMJ Open. 2013;3.

10. Zhu Y, Wang PP, Zhao J, Green R, Sun Z, Roebothan B, et al. Dietary $\mathrm{N}$-nitroso compounds and risk of colorectal cancer: a case-control study in Newfoundland and Labrador and Ontario, Canada. Br J Nutr. 2014;111:1109-17.

11. Yan J, Liu L, Roebothan B, Ryan A, Chen Z, Yi Y, et al. A preliminary investigation into diet adequacy in senior residents of Newfoundland and Labrador, Canada: a cross-sectional study. BMC Public Health. 2014;14:302.

12. Sun Z, Zhu Y, Wang PP, Roebothan B, Zhao J, Dicks E, et al. Reported intake of selected micronutrients and risk of colorectal cancer: results from a large population-based case-control study in Newfoundland, Labrador and Ontario, Canada. Anticancer Res. 2012;32:687-96.

13. Sun Z, Liu L, Wang PP, Roebothan B, Zhao J, Dicks E, et al. Association of total energy intake and macronutrient consumption with colorectal cancer risk: results from a large population-based case-control study in Newfoundland and Labrador and Ontario, Canada. Nutr J. 2012;11:18.

14. Chen Z, Wang PP, Woodrow J, Zhu Y, Roebothan B, McLaughlin JR, et al Dietary patterns and colorectal cancer: results from a Canadian population-based study. Nutr J. 2015;14:8.

15. Zhao J, Halfyard B, Roebothan B, West R, Buehler S, Sun Z, et al Tobacco smoking and colorectal cancer: a population-based case-control study in Newfoundland and Labrador. Can J Public Health. 2010;101:281-9.

16. Liu L, Wang PP, Roebothan B, Ryan A, Tucker CS, Colbourne J, et al. Assessing the validity of a self-administered food-frequency questionnaire (FFQ) in the adult population of Newfoundland and Labrador, Canada. Nutr J. 2013:12:49.

17. Wang PP, Dicks E, Gong X, Buehler S, Zhao J, Squires J, et al. Validity of random-digit-dialing in recruiting controls in a case-control study. Am J Health Behav. 2009;33:513-20.

18. Willett W. Nutritional epidemiology. 2nd ed. New York: Oxford University Press; 1998.

19. Stram DO, Hankin JH, Wilkens LR, Pike MC, Monroe KR, Park S, et al. Calibration of the dietary questionnaire for a multiethnic cohort in Hawaii and Los Angeles. Am J Epidemiol. 2000;151:358-70.

20. Fluge O, Gravdal K, Carlsen E, Vonen B, Kjellevold K, Refsum S, et al. Expression of $\mathrm{EZH} 2$ and $\mathrm{Ki}-67$ in colorectal cancer and associations with treatment response and prognosis. Br J Cancer. 2009;101:1282-9.

21. Takata Y, Maskarinec G, Franke A, Nagata C, Shimizu H. A comparison of dietary habits among women in Japan and Hawaii. Public Health Nutr. 2004;7:319-26

22. Stram DO, Longnecker MP, Shames L, Kolonel LN, Wilkens LR, Pike MC et al. Cost-efficient design of a diet validation study. Am J Epidemiol. 1995:142:353-62

23. ESHA Food Processor. [http://www.esha.com/foodprosql].

24. Cerny BA, HFK. A study of a measure of sampling adequacy for factor-analytic correlation matrices. Multivar Behav Res. 1977;12:43-7.

25. Yang EJ, Kerver JM, Song WO. Dietary patterns of Korean Americans described by factor analysis. J Am Coll Nutr. 2005;24:115-21.

26. van Dam RM, Rimm EB, Willett WC, Stampfer MJ, Hu FB. Dietary patterns and risk for type 2 diabetes mellitus in U.S. men. Ann Intern Med. 2002;136:201-9.

27. Walker M, Aronson KJ, King W, Wilson JW, Fan W, Heaton JP, et al. Dietary patterns and risk of prostate cancer in Ontario, Canada. Int J Cancer. 2005:116:592-8.

28. Magalhaes B, Peleteiro B, Lunet N. Dietary patterns and colorectal cancer: systematic review and meta-analysis. Eur J Cancer Prev. 2012;21:15-23.

29. Eilat-Adar S, Mete M, Fretts A, Fabsitz RR, Handeland V, Lee ET, et al. Dietary patterns and their associationwith cardiovascular risk factors in a population undergoing lifestyle changes: The Strong Heart Study. Nutr Metab Cardiovasc Dis. 2013;23(6):528-35.

30. Kerver JM, Yang EJ, Bianchi L, Song WO. Dietary patterns associated with risk factors for cardiovascular disease in healthy US adults. Am J Clin Nutr. 2003;78:1103-10

31. Naja F, Nasreddine L, Itani L, Chamieh MC, Adra N, Sibai AM, et al. Dietary patterns and their association with obesity and sociodemographic factors in a national sample of Lebanese adults. Public Health Nutr. 2011;14:1570-8.

32. History of Newfoundland Cod Fishery. [https://www.cdli.ca/cod/history5.htm]

33. Park SY, Murphy SP, Wilkens LR, Yamamoto JF, Sharma S, Hankin JH, et al. Dietary patterns using the Food Guide Pyramid groups are associated with sociodemographic and lifestyle factors: the multiethnic cohort study. J Nutr. 2005;135:843-9.

34. Bamia C, Orfanos P, Ferrari P, Overvad K, Hundborg HH, Tjonneland A, et al Dietary patterns among older Europeans: the EPIC-Elderly study. Br J Nutr. 2005;94:100-13. 
35. Stricker MD, Onland-Moret NC, Boer JM, van der Schouw YT, Verschuren WM, May AM, et al. Dietary patterns derived from principal component- and k-means cluster analysis: long-term association with coronary heart disease and stroke. Nutr Metab Cardiovasc Dis. 2013;23(3):250-6.

36. Kurotani K, Budhathoki S, Joshi AM, Yin G, Toyomura K, Kono S, et al. Dietary patterns and colorectal cancer in a Japanese population: the Fukuoka Colorectal Cancer Study. Br J Nutr. 2010;104:1703-11.

37. Mizoue T, Yamaji T, Tabata S, Yamaguchi K, Shimizu E, Mineshita M, et al. Dietary patterns and colorectal adenomas in Japanese men: the Self-Defense Forces Health Study. Am J Epidemiol. 2005;161:338-45.

38. Satia JA, Tseng M, Galanko JA, Martin C, Sandler RS. Dietary patterns and colon cancer risk in Whites and African Americans in the North Carolina Colon Cancer Study. Nutr Cancer. 2009;61:179-93.

39. Schulze MB, Hoffmann K, Kroke A, Boeing H. Dietary patterns and their association with food and nutrient intake in the European Prospective Investigation into Cancer and Nutrition (EPIC)-Potsdam study. Br J Nutr. 2001;85:363-73.

40. Chen Z, Liu L, Roebothan B, Ryan A, Colbourne J, Baker N, et al. Four major dietary patterns identified for a target-population of adults residing in Newfoundland and Labrador, Canada. BMC Public Health. 2015;15:69.

\section{Submit your next manuscript to BioMed Central and take full advantage of:}

- Convenient online submission

- Thorough peer review

- No space constraints or color figure charges

- Immediate publication on acceptance

- Inclusion in PubMed, CAS, Scopus and Google Scholar

- Research which is freely available for redistribution 